\title{
Predictive Modeling and Detection of Insulation Failure in a Natural Gas Pipeline Transmission System
}

\author{
Orga, A.C; Okure, V; Awheme, E; Obibuenyi, J.I; Anusi,M; Emelu,C. \\ Department of Chemical Engineering; Federal University of Technology, Owerri; Imo State; Nigeria.
}

\begin{abstract}
In this paper, a model/software that can predict insulation failure in a natural gas pipeline transmission system was developed by applying established principles of heat flow and gas dynamics. By using the model/software, one will not only know when insulation failure occurred but the location in the long distance pipeline where it occurs. This will reduce the problems associated with late detection, with its adverse consequences such as hydrate formation and pipeline blockage, and explosion and fire!
\end{abstract}

\section{Introduction}

In natural gas pipeline transmission systems, insulation is performed to reduce heat losses from the pipe. Corrosion, excavation,, natural forces, incorrect operation and other forces(such as pipeline vandalization, accidents, etc. ,may lead to insulation failure [Offshore Technology Report, OTO 98 162, 1998)]. If insulation is working properly, then the only loss will be due to frictional resistances and the gas would be delivered at the expected temperature and pressure conditions. However if insulation fails, then there will be additional heat losses apart from that due to fictional resistances, thus the gas will be delivered at a lower temperature, and excessive heat losses, may cause operational problems such as hydrate formation and blockage of pipelines and explosion which ,may be accompanied by fire!, thus the need to detect failure quickly to avoid these adverse consequences [Taylor, J. R. 1994]: [“http://ops.dot.gov/stats/stats.htm", 2009.]. Current failure detection methods include right of way inspection and computational pipeline modeling involving elaborate dynamic simulators and extensive field data collection and analyses, which because of the subsea/swampy and difficult terrain of the usual pipeline right of way and the huge costs, makes them difficult to detect early failures. Thus in this paper, a predictive model/software that can detect early insulation failures in natural gas pipeline transmission systems was developed and is presented.

\section{Modeling}

The predictive model/software was based on heat conduction and Fourier's equation of one dimensional steady heat flow in a hollow cylinder [D. Rajshput, 2009], [Welty, J., C. E. et al, 2008], [A. Herrán-González, et al, 2009], which is given by:

$$
q_{n}=-K A \frac{d T}{d r}
$$

The heat flux $q_{n}\left(\mathrm{~W} / \mathrm{m}^{2}\right)$ is the heat transfer rate in the $\mathrm{n}$ direction per unit area perpendicular to the direction of the heat flow (that is the radial direction)

$\boldsymbol{K}(\mathrm{W} / \mathrm{m} . \mathrm{K})$ is the thermal conductivity of the pipeline in the direction $\boldsymbol{n}$.

A $(\mathbf{2} \boldsymbol{R} \mathbf{R} \mathbf{L})$ is the total surface area, where $\boldsymbol{R}$ is the internal radius of the pipeline and $\boldsymbol{L}$ is the length of the pipeline in meters.

$\frac{d T}{d r}(\mathrm{~K} / \mathrm{m})$ is the temperature gradient in the direction $\mathrm{n}$

Thus consider an un-insulated gas pipeline of length, $\mathrm{L}$ as shown in fig. 11 

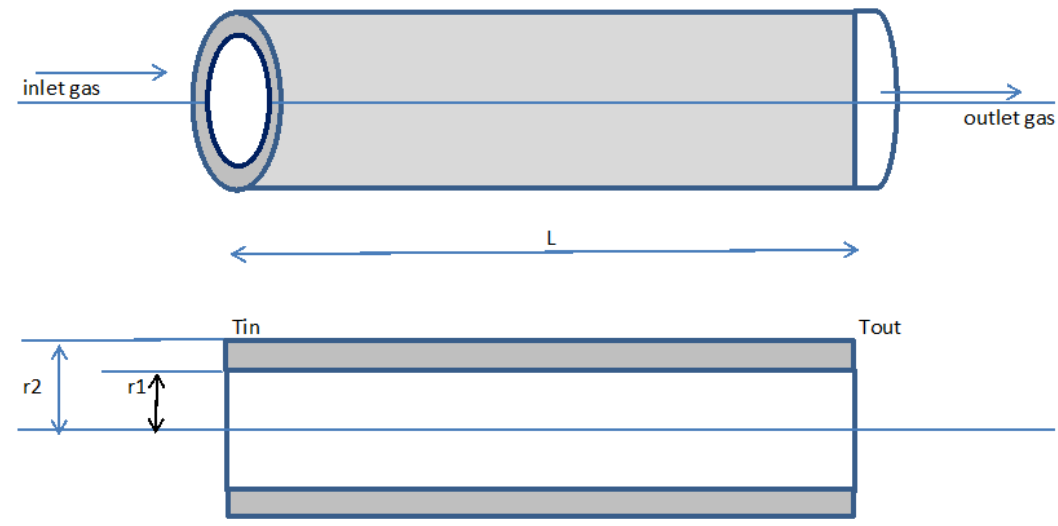

Fig.1-1. An uninsulated natural gas pipeline

Heat loss from the pipe comprise of three (3) kinds [Perry, R. H., 1997].)[M. Abbaspour, 2008].[K. Gersten, 2001] namely:

1. Heat loss by convection from the inside pipe fluid

2. Heat loss by conduction across the pipe thickness: r2-r1

3. Heat loss by convection to the outside pipe fluid

Thus the overall heat loss, $\mathrm{Q}$ is given in terms of the temperature gradient between the inside fluid, Ti and the outside fluid, To and the thermal resistances of the 3 kinds above as:

$$
Q=\Delta T / \sum R_{i}, \quad i=1,2,3
$$

Where

$\Delta T=T_{i}-T_{o}$

$\sum R_{i}$, the thermal resistances of the 3 kinds as shown in fig.1.2.

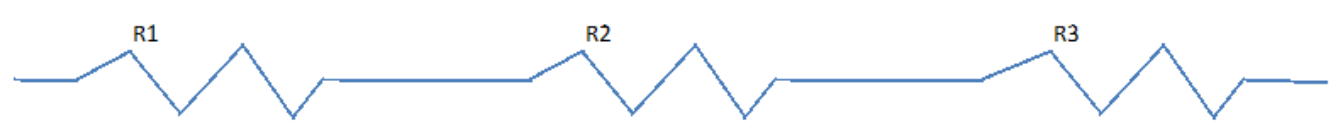

Therefore

Fig.1.2 : thermal resistances of uninsulated pipeline wall segments

$Q=$ Ti-To

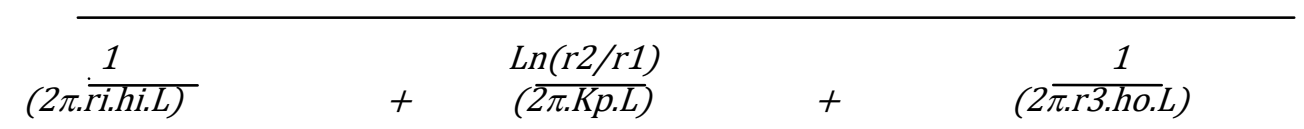

In the case where the heat coefficients, hi, ho, are very large (the usual case in natural gas pipelines), the first and last terms in the denominator of eq.1.3 approximate zero, thus the equation reduces to:

$Q=$

$$
\frac{T_{i}-T_{o}}{\frac{\operatorname{Ln}(r 2 / r 1)}{(2 \pi \cdot K p \cdot L)}}
$$

Rearranging:

$$
Q=\frac{2 \pi K p L \cdot\left(T_{i}-T_{o}\right)}{\operatorname{Ln}\{(r 2 / r 1)\}}
$$


This heat loss causes temperature drop in the flowing fluid, thus the overall heat loss is[Ouyang, L., and $\mathrm{K}$. Aziz, 1996]:

$Q=\operatorname{MCp}\left(T_{\text {in }}-T_{\text {out }}\right)$

But

$$
T_{i}=\left(T_{\text {in }}+T_{\text {out }}\right) / 2
$$

Combining equations and rearranging:

$$
\text { Tout }=\frac{\{\alpha 1-L / 2)}{\{\alpha 1+L / 2)} T_{\text {in }}+\frac{\{L\}}{\{\alpha 1+L / 2\}} T_{o}
$$

Where

$$
\alpha 1=\frac{M C p \cdot \operatorname{Ln}(r 2 / r 1)}{2 \pi K p}
$$

, which gives the outlet temp for the case of no insulator (naked pipe). If the pipe is now insulated as shown in fig 1.3:
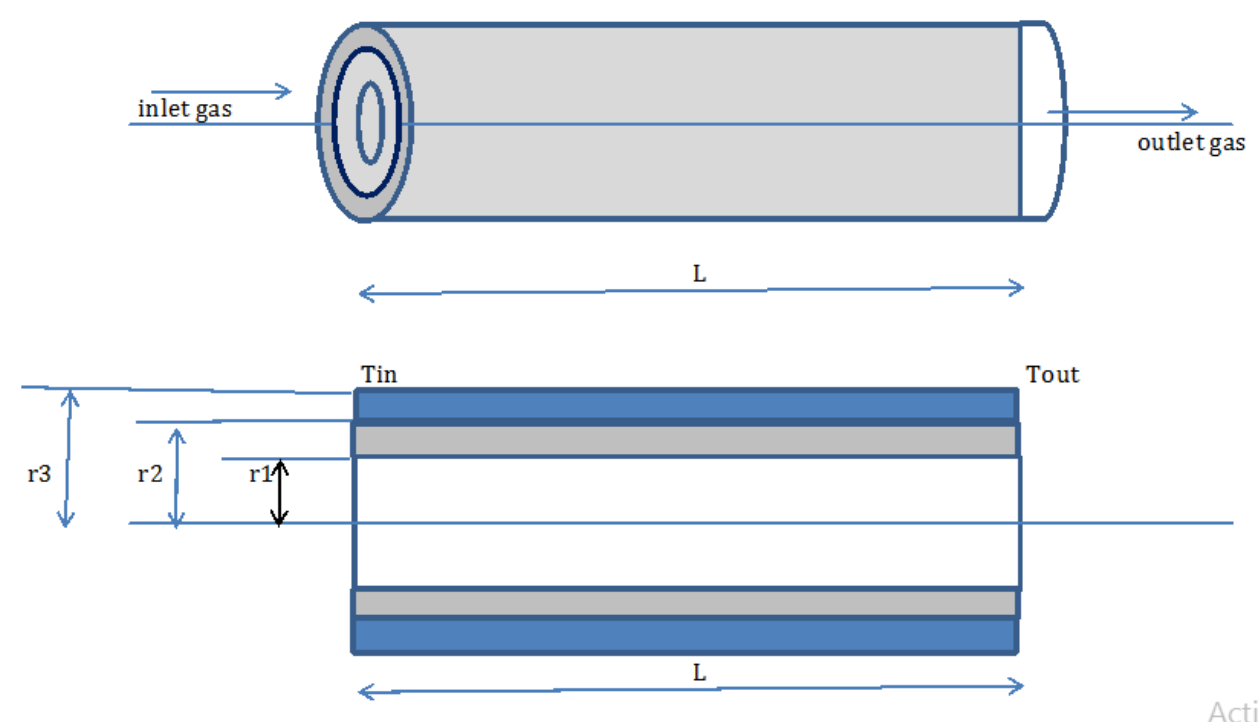

Fig.1.3: an insulated natural gas pipeline

Heat loss from the pipe comprise of 4 kinds namely:

1. heat loss by convection from the inside pipe fluid

2. heat loss by conduction across the pipe thickness: r2-r1

3. heat loss by conduction across the insulator thickness: r3-r2

4. heat loss by convection to the outside pipe fluid

Thus the overall heat loss, $\mathrm{Q}$ is given in terms of the temperature gradient between the inside fluid, Ti and the outside fluid, $T_{\mathrm{o}}$ and the thermal resistances of the 4 kinds above as:

$Q=\Delta T / \sum R_{i}, \quad i=1-4$

Where

$\Delta T=T_{i}-T_{o}$

$\sum R i$, the thermal resistances of the 4 kinds as shown in the fig1.4. 


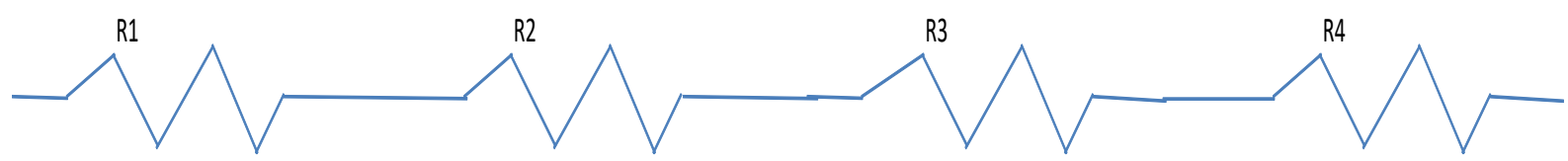

Fig.1. 4 : thermal rresistances of insulated pipeline wall segments

Therefore

$Q=$ $T_{i^{-}} T_{o}$

$\overline{\frac{1}{(2 \pi \cdot r i \cdot h i \cdot L)}+\frac{\operatorname{Ln}(r 2 / r 1)}{(2 \pi \cdot K p \cdot L}+\frac{\operatorname{Ln}(r 3 / r 2)}{(2 \pi \cdot K i n s . L)}+\frac{1}{(2 \pi \cdot r 3 \cdot h o \cdot L)}}$

In this case where the heat coefficients, hi, ho, are very large, the equation reduces to:

$Q=$

$$
\frac{T_{i}-T_{o}}{\frac{\operatorname{Ln}(r 2 / r 1)}{(2 \pi . K p . L)}}+\frac{\operatorname{Ln}(r 3 / r 2)}{(2 \pi \cdot \text { Kins.L })}
$$

Rearranging:

$$
Q=\frac{2 \pi K p \cdot K_{i} \cdot L \cdot\left(T_{i}-T_{o}\right)}{\operatorname{Ln}\left\{(r 2 / r 1)^{K i} \cdot(r 3 / r 2)^{K p}\right\}}
$$

This heat loss causes temperature drop in the flowing fluid, thus the overall heat loss is:

$Q=M \cdot C p\left(T_{\text {in }}-T_{\text {out }}\right)$

But

$T_{i}=\left(T_{\text {in }}+T_{\text {out }}\right) / 2$

Combining equations $1.13,1.14,1.15$ and rearranging:

$$
T_{\text {out }}=\frac{\{\alpha 2-L / 2\}}{\{\alpha 2+L / 2)} T_{\text {in }}+\underset{\{\alpha 2+L / 2\}}{\{L\}}
$$

Where

$$
\alpha 2=\frac{\left.M C p \cdot \operatorname{Ln}\left\{(r 2 / r 1)^{K i} \cdot(r 3 / r 2)^{K p}\right)\right\}}{2 \pi K p K_{i}}
$$

, which gives the outlet temp for the case of no insulation failure.

If insulation failure, of thickness $t$, now occurs at length $\mathrm{X}$ from the beginning of the pipe, as shown in fig 1.5. 


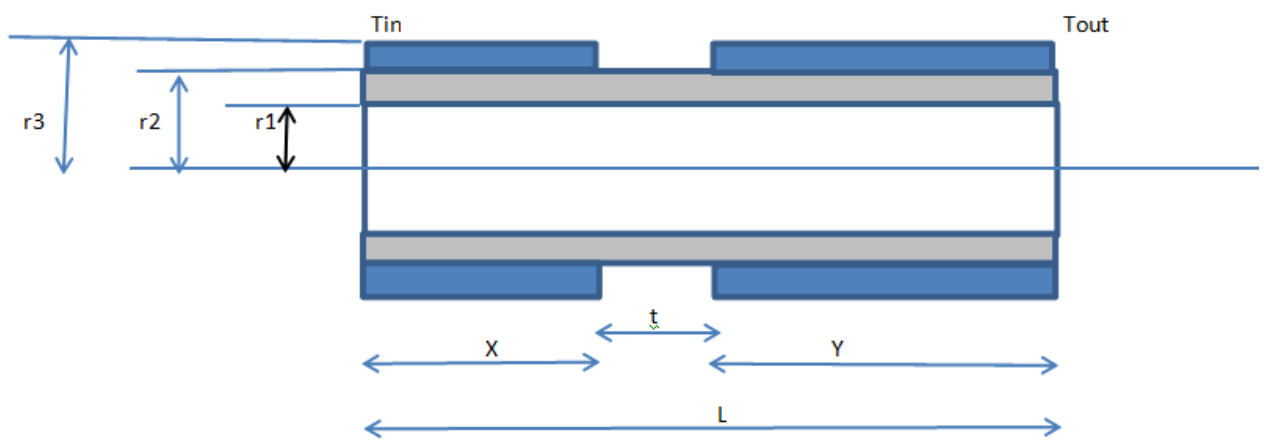

Fig.1.5. an natural gas pipeline for the case of insulation failure

Thus while the heat losses (and the exit temperatures) from the no insulation failure segments; $\mathrm{X}$ and $\mathrm{Y}$ are determined from eqs1.13 and 1.16. And, for the case of insulation failure segment, $\mathrm{X}$, the heat loss is determined from eqs 1.5 and 1.8. Thus, using the equations, the exit temperatures, $T_{1}, T_{2}, T_{\text {out }}$, in each segment can be determined as follows:

$$
\begin{aligned}
& T_{1}=\left(\frac{\alpha 2-X / 2}{\alpha 2+X / 2}\right)^{T_{i n}}+\left(\frac{X}{\alpha 2+X / 2}\right)^{T_{o}} \\
& T_{2}=\left(\frac{\alpha 1-t / 2}{\alpha 1+t / 2}\right)^{T_{1}+}\left(\frac{t}{\alpha 1+t / 2}\right)^{T_{o}} \\
& T_{\text {out }}=\left(\frac{\alpha 2-Y / 2}{\alpha 2+Y / 2}\right)^{T_{2}}+\left(\frac{Y}{\alpha 2+Y / 2}\right)^{T_{o}}
\end{aligned}
$$

Combining to eliminate the intermediate temperatures, we have:

$$
\begin{aligned}
& \mathrm{T}_{\text {out }}=\left(\frac{(\alpha 2-\mathrm{X} / 2)(\alpha 1-\mathrm{t} / 2)(\alpha 2-\mathrm{Y} / 2)}{(\alpha 2+\mathrm{X} / 2)(\alpha 1+\mathrm{t} / 2)(\alpha 2+\mathrm{Y} / 2)}\right)^{\mathrm{T}_{\text {in }}} \\
& \quad+\left(\frac{\mathrm{X}(\alpha 1-\mathrm{t} / 2)(\alpha 2-\mathrm{Y} / 2)}{(\alpha 2+\mathrm{X} / 2)(\alpha 1+\mathrm{t} / 2)(\alpha 2+\mathrm{Y} / 2)}+\frac{\mathrm{t}(\alpha 2-\mathrm{Y} / 2)}{(\alpha 1+\mathrm{t} / 2)(\alpha 2+\mathrm{Y} / 2)}+\frac{\mathrm{Y}}{(\alpha 2+\mathrm{Y} / 2}\right)^{\mathrm{T}_{0}}
\end{aligned}
$$

Note that

$$
Y=L-X-t
$$

\begin{tabular}{|c|c|}
\hline Pipe & \\
\hline Nominal external diameter $\mathrm{mm}$ & 622.2 \\
\hline Wall thickness, $\mathrm{mm}$ & 22.2 \\
\hline Pipe thermal conductivity $\mathrm{W} \backslash \mathrm{mK}$ (carbon steel) & 45.35 \\
\hline \multicolumn{2}{|l|}{ Insulation } \\
\hline Concrete thickness $\mathrm{mm}$ & 50 \\
\hline Concrete thermal conductivity $\mathrm{W} / \mathrm{mK}$ (high density concrete) & 2.67 \\
\hline \multicolumn{2}{|l|}{ Temperature profile } \\
\hline \multicolumn{2}{|l|}{ Fluid } \\
\hline$\left({ }^{\circ} \mathrm{C}\right)$ & 45.94 \\
\hline OD of pipe $\left({ }^{\circ} \mathrm{C}\right)$ & 45.58096 \\
\hline
\end{tabular}

Equation 1.21 gives the outlet temperature as a function of the thickness, $t$ of insulation failure and the distance, $\boldsymbol{x}$ from the pipe inlet where it occurs.

\section{Simulation}

Table 1.1 below shows typical data/operating conditions of a gas pipeline:

Table 1.1 Typical data/operating conditions of a gas pipeline: 


\begin{tabular}{|l|l|}
\hline OD of coating 1 & \\
\hline$\left({ }^{\circ} \mathrm{C}\right)$ & 37.77258 \\
\hline OD of coating 2 & \\
\hline$\left({ }^{\circ} \mathrm{C}\right)$ & 18.81682 \\
\hline Ambient $\left({ }^{\circ} \mathrm{C}\right)$ & 15 \\
\hline Operating conditions & \\
\hline Gas flow rate MMSCFD & 749.8658 \\
\hline Inlet temperature ${ }^{\circ} \mathrm{C}$ & 60 \\
\hline Inlet pressure bar & 147.5 \\
\hline Ambient temperature ${ }^{\circ} \mathrm{C}$ & 15 \\
\hline Gas properties & \\
\hline Gas gravity kg/m 3 & 0.182 \\
\hline Gas specific heat capacity JkgK & 2170 \\
\hline
\end{tabular}

The modeling in the previous section showed outlet temperatures for the three possible conditions as follows:

Case 1: temp for the case of no insulator (naked pipe)

Case 2: outlet temp for the case of no insulation failure

Case 3: outlet temperature for the case of insulation failure at length, $\mathrm{X}$ from pipeline inlet

Using the equations above and the data in table 1.1, the outlet temperatures in each case are generated, for varying failure length, $\mathrm{X}$ and constant thickness, $\mathrm{t}$

A Spreadsheet template (MS Excel Visual Basic edited code) was developed and used.

The results are shown graphically in fig.1.6.

\section{Results and Analyses}

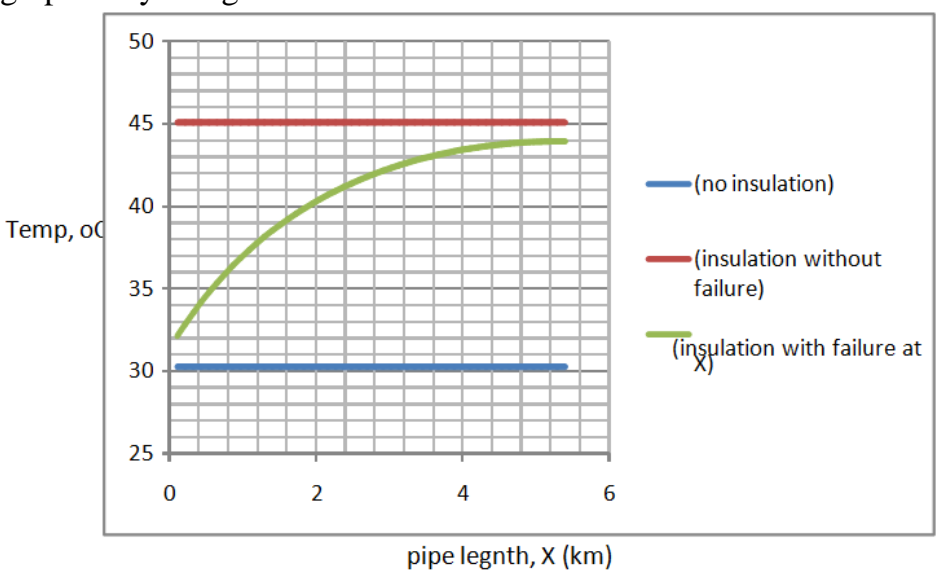

Fig.1.6. Exit temp.for the case of insulation failure thickness, $t$ of $0.01 \mathrm{~L}$ ) vs pipe distance, $X$

Thus for gas pipeline inlet temperature of $45.57^{\circ} \mathrm{C}$, the exit temperature for a span of $5.4 \mathrm{~km}$ is $45^{\circ} \mathrm{C}$ for the case of normal operation of no insulation failure, while that of non insulated pipe is constant at $30^{\circ} \mathrm{C}$ showing that more heat is lost for non insulated pipe. Of the effect becomes, more pronounced in long distant pipelines for the insulation failure case, the temperature is lowest if the failure occurs at the inlet of the pipe and rises exponentially towards the non failure case at the end of the pipe.

\section{Conclusion}

In this project, a simple but efficient model that can predict insulation failure in a natural gas pipeline was developed by applying established principles of heat flow and gas dynamics. All that is required are the inlet and exit temperature/flowrate of the pipeline. By using the model, one will not only know when insulation failure occurred but the location in the long distance pipeline where it occurs. This will reduce the problems associated with late detection, with its adverse consequences such as hydrate formation and pipeline blockage, and possibly explosion/fire!

\section{References}

[1] Abbaspour, M, K.S. Chapman, "Nonisothermal transient flow in natural gas pipeline" J. Appl. Mech. Trans. ASME, 75 (3) (2008), pp. 0310181-0310188)

[2] Gersten,K , H.D. Papenfuss, T. Kurschat, F. Genillon, P. Fernandez, N. Ravell $\square$ Heat transfer in gas pipelines $\square$ Oil Gas Eur. Mag., 27 (1) (2001), pp. 30-34)

[3] Offshore Technology Report, OTO 98 162, Subsea hydrocarbon pipeline failure: survey of available prediction schemes, HSE, (1998). 
[4] Ouyang, L., and K. Aziz, "Steady-state gas flow in pipes,” J. Pet. Sci. Eng., 14, 137 (1996)

[5] Perry, R. H., and D. W. Green, Perry's chemical engineers' handbook, 7th Ed., McGraw Hill, London (1997).)

[6] Rajshput, D. (2009): Heat and Mass transfer $7^{\text {th }}$ Edition, PHI Learning Private Limited.],[ Welty, J., C. E. Wicks,

[7] Rorrer, G.L., and R. E. Wilson, Fundamentals of Momentum, LHeat and Mass Transfer, 5th Edition, John Wiley \& Sons (2008),] ( A. Herrán-González, J.M. De La Cruz, B. De Andrés-Toro, J.L. Risco-Martın Modeling and simulation of a gas distribution pipeline network $\square$ Appl. Math. Model., 33 (2009), pp. 1584-1600)

[8] Taylor, J. R. (1994): Risk Analysis for Process Plant, Pipelines and Transport, London: E \& FN Spon]

[9] US Department of Transportation - Office of Pipeline Safety, “http://ops.dot.gov/stats/stats.htm”, (2009) 